\title{
Packaging related properties of commercially available biopolymers - An overview of the status quo
}

\author{
V. Jost ${ }^{1,2 *}$ \\ ${ }^{1}$ Technical University of Munich, TUM School of Life Sciences Weihenstephan, Chair of Food Packaging Technology, \\ 85354 Freising, Germany \\ ${ }^{2}$ Fraunhofer Institute for Process Engineering and Packaging IVV, Giggenhauser Strasse 35, 85354 Freising, Germany
}

Received 19 October 2017; accepted in revised form 14 December 2017

\begin{abstract}
Several commercially available thermoplastic biopolymers were processed in a continuous extrusion line. The molecular weight, crystallinity, and mechanical and permeation properties of the cast films were determined in order to evaluate the status quo of biopolymers currently commercially available. The biopolymers that were evaluated were polylactic acid (PLA), several polyhydroxyalkanoates (PHAs) (Poly(3-hydroxybutyrate) (PHB), poly(3-hydroxybutyrate-co-4-hydroxybutyrate) (PHBHB), poly(3-hydroxybutyrate-co-3-hydroxyvalerate) (PHBV)), thermoplastic starch (TPS), polybutylene adipate terephthalate (PBAT), polybutylene succinate (PBS), polycaprolactone (PCL) and biobased polyethylene (BioPE). Due to its potential for biobased production, thermoplastic polyurethane elastomer (TPU) was also analysed. Mechanical analysis showed the PLA and PHA films had high strength and extremely low elongation at break. These were also the materials with the highest molecular weights. Films made of TPU, PCL, TPS, PBAT and BioPE had a significantly lower Young's modulus and significantly higher elongation at break; these films had comparatively low molecular weights. Permeation measurements showed that PHA films, and particularly PHBV, had the lowest oxygen and water vapour permeability of the biopolymers that were analysed. The biopolymers BioPE, TPS, PCL, TPU and PBAT were highly permeable to oxygen, and had comparatively low molecular weight. The biopolymers TPU, PBS, PBAT, PCL and TPS were highly permeable to water vapour.
\end{abstract}

Keywords: biopolymers, biocomposites, extruded cast films, permeability, mechanical properties

\section{Introduction}

Numerous studies have analysed the properties of thermoplastic biopolymers, but most of those biopolymers have been processed on a laboratory scale. The present study aims to give the status quo of commercially available biopolymers that have been processed in a continuous pilot plant (pre-industrial scale). This overview describes several packaging related characteristics of the films such as molecular weight, crystallinity and their mechanical (Young's modulus, tensile strength, elongation at break) and permeation properties (water vapour and oxygen permeability). All the materials were processed in a continuous flat film extrusion line with a low temperature profile to minimise heat induced degradation of the biopolymers. Processing under the same conditions enables a comparison of the different biopolymer films. Biopolymers are defined in this study as polymers that are biobased, biodegradable or both [1]. From each of these three groups, at least one material was analysed: Biopolymers that are biobased and biodegradable include polylactic acid (PLA), polyhydroxyalkanoates (PHAs) and a thermoplastic starch (TPS) based material. Since PHAs show interesting permeation properties, several types of PHA were studied: Poly(3-hydroxybutyrate) (PHB), three types of poly(3-hydroxybutyrate-co-3-hydroxyvalerate) (PHBV) with varying 3-hydroxyvalerate (3HV)

"Corresponding author, e-mail: Verena.Jost@ivv.fraunhofer.de C BME-PT 
content, three types of poly(3-hydroxybutyrate-co4-hydroxybutyrate) (PHBHB) with varying 3-hydroxybutyrate (3HB) content and a blend of PHBHB with PLA+filler. The group of biopolymers that are nonbiobased but biodegradable includes the following materials: three polybutylene adipate terephthalate (PBAT) based materials (amongst other things in combination with PLA or PLA+filler), polybutylene succinate (PBS) and polycaprolactone (PCL). The group of biopolymers that are biobased and non-biodegradable is represented by biobased polyethylene (BioPE). Additionally, a fossil based thermoplastic polyurethane elastomer (TPU) was included in this study because of its potential for biobased production $[2-4]$.

\section{Materials and methods}

\subsection{Materials}

Data about the biopolymer materials are summarised in Table 1.

\subsection{Methods}

All granulates were treated by a convective pre-drying step at $60^{\circ} \mathrm{C}$ for 24 hours to remove residual

Table 1. Data about the biopolymers according to the material data sheets.

\begin{tabular}{|c|c|c|c|c|c|c|}
\hline Sample & Producer/distributor & Grade & $\begin{array}{c}T_{\mathbf{m}} \\
{\left[{ }^{\circ} \mathbf{C}\right]}\end{array}$ & \begin{tabular}{|c|} 
MFI \\
{$\left[\mathrm{g} \cdot 10 \mathrm{~min}^{-1}\right]$} \\
$($ applied conditions $)$
\end{tabular} & $\begin{array}{c}\text { Density } \\
\rho \\
{\left[\mathrm{g} \cdot \mathrm{cm}^{-3}\right]}\end{array}$ & Remarks \\
\hline PLA & $\begin{array}{l}\text { NatureWorks LLC, MN, } \\
\text { USA via Resinex Germany } \\
\text { GmbH, Zwingenberg, Ger- } \\
\text { many }\end{array}$ & $2002 \mathrm{D}$ & 210 & $\begin{array}{c}4-8 \\
\left(190^{\circ} \mathrm{C}, 2.16 \mathrm{~kg}\right)\end{array}$ & 1.24 & \\
\hline PHB & Biomer, Krailling, Germany & P209 & & $\begin{array}{c}10 \\
\left(180^{\circ} \mathrm{C}, 2.16 \mathrm{~kg}\right)\end{array}$ & 1.2 & \\
\hline PHBV3 & $\begin{array}{l}\text { Ningbo Tianan Biologic } \\
\text { Material Co., Ltd. in Ning- } \\
\text { bo, China }\end{array}$ & $\begin{array}{l}\text { Enmat } \\
\text { Y1000P }\end{array}$ & $\sim 170-176$ & & 1.25 & $\begin{array}{l}3 \mathrm{HV} \text { content: } \\
3 \mathrm{~mol} \%{ }^{*}\end{array}$ \\
\hline PHBV7 & $\begin{array}{l}\text { PHB Industrial S/A, Serrana } \\
\text { SP, Brasil }\end{array}$ & Biocycle & $\sim 170$ & & & $\begin{array}{l}3 \mathrm{HV} \text { content: } \\
7 \mathrm{~mol}^{*}{ }^{*}\end{array}$ \\
\hline PHBV11 & Nature Plast, IFS, France & PHI 002 & $145-155$ & & 1.25 & $\begin{array}{l}3 \mathrm{HV} \text { content: } \\
1 \mathrm{~mol} \%{ }^{*}\end{array}$ \\
\hline PHBHB18 & \multirow{3}{*}{$\begin{array}{l}\text { Shandong Ecomann Tech- } \\
\text { nology Co., Ltd., Shandong, } \\
\text { China }\end{array}$} & EM 20010 & $140-160$ & $\begin{array}{c}8 \\
\left(170^{\circ} \mathrm{C}, 2.16 \mathrm{~kg}\right)\end{array}$ & 1.33 & $3 \mathrm{HB}: 4 \mathrm{HB}=18: 01$ \\
\hline PHBHB13 & & EM 40000 & $140-160$ & $\begin{array}{c}3 \\
\left(170^{\circ} \mathrm{C}, 2.16 \mathrm{~kg}\right)\end{array}$ & 1.24 & $3 \mathrm{HB}: 4 \mathrm{HB}=13: 01$ \\
\hline $\begin{array}{l}\text { PHBHB10 } \\
+ \text { PLA+filler }\end{array}$ & & EM 10070 & $150-160$ & $\begin{array}{c}4 \\
\left(170^{\circ} \mathrm{C}, 2.16 \mathrm{~kg}\right)\end{array}$ & 1.25 & $\begin{array}{l}3 \mathrm{HB}: 4 \mathrm{HB}=10: 01, \\
\mathrm{PLA}<40 \%, \\
\text { mineral filler }<10 \%\end{array}$ \\
\hline TPS & $\begin{array}{l}\text { Novamont SPA, Novara, } \\
\text { Italy }\end{array}$ & $\begin{array}{l}\text { Mater-Bi } \\
\text { P.T.CS }\end{array}$ & 135 & & 1.19 & \\
\hline PBAT & $\begin{array}{l}\text { BASF SE, Ludwigshafen } \\
\text { am Rhein, Germany }\end{array}$ & \begin{tabular}{|c|} 
Ecoflex $^{\circledR} \mathrm{F}$ \\
Blend C1200
\end{tabular} & $110-120$ & & $1.25-1.27$ & \\
\hline PBAT+PLA & $\begin{array}{l}\text { BASF SE, Ludwigshafen } \\
\text { am Rhein, Germany }\end{array}$ & \begin{tabular}{|c|} 
Ecovio $^{\circledR} \mathrm{F}$ \\
Blend C2224
\end{tabular} & $\begin{array}{l}110-120 \text { for PBAT, } \\
140-155 \text { for PLA }\end{array}$ & & $1.24-1.26$ & \\
\hline $\begin{array}{l}\text { PBAT+PLA } \\
+ \text { filler }\end{array}$ & $\begin{array}{l}\text { Metabolix GmbH, Cologne, } \\
\text { Germany (now BIO-FED, } \\
\text { AKRO-Plastic GmbH, } \\
\text { Cologne, Germany) }\end{array}$ & $\begin{array}{c}\text { Mvera }^{\circledR} \\
\text { B5010 }\end{array}$ & 166 & & 1.4 & Mineral filler \\
\hline PBS & $\begin{array}{l}\text { Mitsubishi Chemical Corpo- } \\
\text { ration via Helian Polymers } \\
\text { BV, Venlo, Netherlands }\end{array}$ & $\begin{array}{l}\text { GS Pla }{ }^{\circledR} \\
\text { FD92WN }\end{array}$ & 84 & & 1.24 & \\
\hline PCL & $\begin{array}{l}\text { Perstorp Holding AB, } \\
\text { Malmö, Sweden }\end{array}$ & Capa 6500 & $58-60$ & & & \\
\hline TPU & $\begin{array}{l}\text { BASF Polyurethanes GmbH, } \\
\text { Lemfoerde, Germany }\end{array}$ & $\begin{array}{l}\text { Elastollan }^{(B)} \\
880 \mathrm{~A} 13 \mathrm{~N}\end{array}$ & & $\begin{array}{c}15-25 \\
\left(190^{\circ} \mathrm{C}, 3.8 \mathrm{~kg}\right)\end{array}$ & 1.2 & \\
\hline BioPE & $\begin{array}{l}\text { Braskem S.A., São Paulo, } \\
\text { Brazil }\end{array}$ & $\begin{array}{l}\text { SLL218 } \\
\text { LLDPE }\end{array}$ & & $\begin{array}{c}2.3 \\
\left(190^{\circ} \mathrm{C}, 2.16 \mathrm{~kg}\right)\end{array}$ & 0.918 & $\begin{array}{l}\text { minimum biobased } \\
\text { content: } 87 \%\end{array}$ \\
\hline
\end{tabular}

*As no information was provided on the data sheet, an external service provider (Novamont S.p.A., Italy, Novara) analysed the HV content by Nuclear Magnetic Resonance (NMR) spectroscopy 
moisture before further processing. The pure materials were processed in a flat film extrusion plant type E30 M (30 mm screw, 30D barrel length, $300 \mathrm{~mm}$ nozzle width) manufactured by Dr. Collin $\mathrm{GmbH}$, Ebersberg, Germany. The temperature profile was set at $60-150-165-165-160-160{ }^{\circ} \mathrm{C}$ in order to minimise heat-induced degradation and the rotational speed was set at $30 \mathrm{rpm}$. The cast films had a thickness of $\sim 70-80 \mu \mathrm{m}$.

Crystallinity $(\chi)$ was analysed according to DIN EN ISO 11357-1 by differential scanning calorimetry. A DSC 821e instrument (Mettler-Toledo GmbH, Gießen, Germany) was used. Each sample was analysed for two heating cycles $\left(10 \mathrm{~K} \cdot \mathrm{min}^{-1}\right.$ from -10 to $\left.200^{\circ} \mathrm{C}\right)$ under a nitrogen atmosphere. The enthalpies of fusion $\Delta H_{\mathrm{c}}(\infty)$ of the entirely crystalline materials are shown in Table 2. Due to the unavailability of $\Delta H_{\mathrm{c}}(\infty)$ for TPU, the crystallinity was calculated using the $\Delta H_{\mathrm{c}}(\infty)$ of PCL because PCL can potentially be used as a base material for synthesising TPU from biodegradable sources [5].

Gel permeation chromatography (GPC) was performed as a relative measurement with a PMMA standard according to DIN 55672 in order to analyse the weight and number average molecular weight $\left(M_{\mathrm{w}}, M_{\mathrm{n}}\right)$ and the polydispersity index $\left(P D I=M_{\mathrm{w}} / M_{\mathrm{n}}\right)$. Each sample was dissolved in a hexafluoroisopropanol (HFIP) solution $\left(2500 \mu \mathrm{g} \cdot \mathrm{g}^{-1}\right)$ for $24 \mathrm{~h}$ under ambient conditions. A two-fold determination was performed and the standard deviation was calculated.

Table 2. Enthalpy of fusion of the biopolymers.

\begin{tabular}{|l|c|c|}
\hline \multicolumn{1}{|c|}{ Sample } & $\begin{array}{c}\Delta \boldsymbol{H}_{\mathbf{c}}(\boldsymbol{\infty}) \\
{\left[\mathbf{J} \cdot \mathbf{g}^{-1}\right]}\end{array}$ & Reference \\
\hline PLA & 93.1 & {$[6]$} \\
\hline PHB & 146.0 & {$[7]$} \\
\hline PHBV3 & 141.1 & {$[8]$} \\
\hline PHBV7 & 134.5 & {$[8]$} \\
\hline PHBV11 & 128.0 & {$[8]$} \\
\hline PHBHB18 & 146.0 & {$[7]$} \\
\hline PHBHB13 & 146.0 & {$[7]$} \\
\hline PHBHB10+PLA+filler & 146.0 & {$[7]$} \\
\hline TPS & 22.1 & {$[9,10]$} \\
\hline PBAT & 114.0 & {$[11]$} \\
\hline PBAT+PLA & 114.0 & {$[11]$} \\
\hline PBAT+PLA+filler & 114.0 & {$[11]$} \\
\hline PBS & 200.0 & {$[12]$} \\
\hline PCL & 135.6 & {$[13]$} \\
\hline TPU & - & \\
\hline BioPE & 290.0 & {$[14]$} \\
\hline
\end{tabular}

Before analysis, each sample was filtered through a $0.2 \mu \mathrm{m}$ PTFE injection filter. Polymethyl methacrylate (PMMA) was used as a calibration standard. The equipment/materials used were as follows: an injector (Dionex ASI100), pump (Gynkotek M300), column $(2 \times$ PSS PFG Linear XL, $7 \mu \mathrm{m}, 300 \times 8 \mathrm{~mm}$, at $40^{\circ} \mathrm{C}$ ), detector (ERMA ERC 7512, refractive index detector) and the eluent (HFIP with $0.02 \mathrm{~mol} \cdot \mathrm{L}^{-1}$ potassium trifluoroacetic acid) with a flow rate of $1.0 \mathrm{~mL} \cdot \mathrm{min}^{-1}$. BioPE could not be analysed due to its non-solubility in HFIP.

The mechanical properties of the films (Young's modulus $(Y M)$, tensile strength $(\sigma)$ and elongation at break $(\varepsilon)$ ) were measured according to DIN EN ISO 527-1. The equipment used was the Z005 Allround Line manufactured by Zwick GmbH\&Co. KG, Ulm, Germany. Analysis was performed in the machine direction with a $5 \mathrm{kN}$ load cell. Ten strips of each sample with a width of $15 \mathrm{~mm}$ and an effective length of $100 \mathrm{~mm}$ were stressed by monoaxial tension at $100 \mathrm{~mm} \cdot \mathrm{min}^{-1}$. Only BioPE was tested with an effective length of $50 \mathrm{~mm}$. To determine $\sigma$, the thickness of each strip was measured five times.

The permeation properties water vapour permeability ( $W V P$ ) $Q_{100 \mathrm{H}_{2} \mathrm{O}}$ and oxygen permeability $(O P)$ $Q_{100 \mathrm{O}_{2}}$ were measured. The water vapour permeability was measured by gravimetric analysis: As laid down in DIN 53122-1, the water vapour transmission rate (WVTR) was analysed at $23^{\circ} \mathrm{C}$ for a gradient of $85 \rightarrow 0 \%$ relative humidity (r. h.). The results (in $\mathrm{g} \cdot \mathrm{m}^{-2} \cdot \mathrm{d}^{-1}$ at the set humidity gradient) were normalised to a partial pressure difference of 1 mbar and a film thickness of $100 \mu \mathrm{m}$ (see Equations (1) and (2)). The resulting values give the normalised water vapour permeability $(W V P)$ (similar to a permeation coefficient) $Q_{100 \mathrm{H}_{2} \mathrm{O}}$ (in $\mathrm{g} \cdot 100 \mu \mathrm{m} \cdot \mathrm{m}^{-2} \cdot \mathrm{d}^{-1} \cdot \mathrm{mbar}^{-1}$ ). The standard deviations of these four-fold determinations are shown as error bars in the diagrams. The oxygen transmission rate (OTR) was analysed using Oxtran Twin devices manufactured by Mocon Inc. according to DIN 53380 Part 3. The permeation was measured at $23{ }^{\circ} \mathrm{C}, 50 \% \mathrm{r}$. h. and an oxygen pressure difference of $\sim 1$ bar. The permeated oxygen was detected by an electrochemical detector $\left(\mathrm{N}_{2}+5 \% \mathrm{H}_{2}\right.$ was used as carrier gas). The results (in $\mathrm{cm}^{3} \cdot$ (STP) $\mathrm{m}^{-2} \cdot \mathrm{d}^{-1}$ ) were normalised to a partial pressure difference of 1 bar and a film thickness of $100 \mu \mathrm{m}$ (see Equations (1) and (2)) so giving the normalised oxygen permeability $(O P) \mathrm{Q}_{100 \mathrm{O}_{2}}$ (in $\mathrm{cm}^{3}$ (STP) 
$\left.100 \mu \mathrm{m} \cdot \mathrm{m}^{-2} \cdot \mathrm{d}^{-1} \cdot \mathrm{bar}^{-1}\right)$. The standard deviations of these two-fold determinations are shown as error bars in the diagrams.

$$
\begin{aligned}
& Q_{100 \mathrm{H}_{2} \mathrm{O}}=\operatorname{WVTR} \cdot \frac{d}{\Delta p \cdot 100} \\
& Q_{100 \mathrm{O}_{2}}=\text { OTR } \cdot \frac{d}{\Delta p \cdot 100}
\end{aligned}
$$

where $d$ is actual film thickness (in $\mu \mathrm{m}$ ); $\Delta p$ partial pressure difference (in mbar for water vapour, in bar for oxygen)

\section{Results}

The results of the crystallinity $(\chi)$ and molecular weight $\left(M_{\mathrm{w}}, M_{\mathrm{n}}, P D I\right)$ analyses are shown in Table 3. Results of Mw are not absolute values but are based on a PMMA standard. The PHBV films had the highest $\chi$ and $M_{\mathrm{w}} . M_{\mathrm{w}}$ decreases when the $3 \mathrm{HV}$ content is increased, while $\chi$ only decreases slightly. TPS, followed by PBAT, PHB and PCL, were also highly crystalline biopolymers. These materials have comparatively low $M_{\mathrm{w}}$ (except PHB). The PLA and PHBHB films showed medium to high $M_{\mathrm{w}}$ compared to the other materials but had low $\chi$. The comparatively high $\chi$ of PBAT is drastically reduced upon combining this with PLA. However, the $M_{\mathrm{w}}$ of PBAT is comparatively low and not drastically changed upon combining this with PLA. Biopolymers with comparatively low $\chi$ and $M_{\mathrm{w}}$ were found to be PBS, PBAT+PLA+filler, PBAT+PLA and TPU.
In the following figures, those polymers with a similar main component are grouped by the same symbol. The mechanical properties (see Figures 1 and 2) reveal the high strength of PLA and PHA films compared to other biopolymer films. All other biopolymers (except PLA and PHAs) show significantly lower Young's moduli (YM: $<600 \mathrm{MPa})$ and tensile strength $(\sigma: 8-43 \mathrm{MPa})$. The stiff and partly brittle PLA and PHA films have an extremely low elongation at break $(\varepsilon)$, while $\varepsilon$ of all other biopolymers is significantly higher with a range from $\sim 40-1260 \%$. The biopolymers TPU, PCL, TPS, PBAT and BioPE

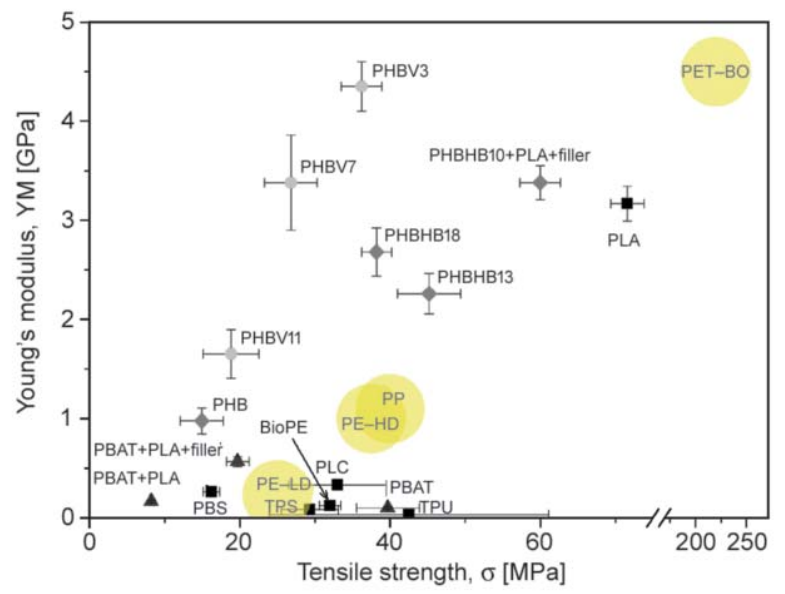

Figure 1. Young's modulus $Y M$ versus tensile strength $\sigma$ for biopolymers with PHBV (•), PHBHB (»), PBATbased materials $(\boldsymbol{\Delta})$ compared with conventional polymers $(\circ)$ according to the literature [17]: YM $[\mathrm{GPa}] / \sigma[\mathrm{MPa}]$ of PE-LD $(0.23 / 25)$, PE-HD $(1.0 /$ 37.5), PET-BO (4.5/220), PP (1.1/40).

\begin{tabular}{|c|c|c|c|c|}
\hline Sample & $\begin{array}{c}\text { Crystallinity } \\
\chi \\
{[-]} \\
\end{array}$ & $\begin{array}{c}\text { Weight average } \\
\text { molecular weight, } M_{\mathrm{w}} \\
{\left[\mathrm{g} \cdot \mathrm{mol}^{-1}\right]}\end{array}$ & $\begin{array}{c}\text { Number average } \\
\text { molecular weight, } M_{\mathrm{n}} \\
{\left[\mathrm{g} \cdot \mathrm{mol}^{-1}\right]}\end{array}$ & $\begin{array}{c}\text { Polydispersity index } \\
\text { PDI } \\
{[-]}\end{array}$ \\
\hline PLA & 0.23 & $177604 \pm 1732$ & $95162 \pm 23345$ & $1.9 \pm 0.45$ \\
\hline PHB & 0.50 & $211368 \pm 417$ & $48709 \pm 426$ & $4.3 \pm 0.03$ \\
\hline PHBV3 & 0.67 & $248368 \pm 2212$ & $79228 \pm 223$ & $3.1 \pm 0.04$ \\
\hline PHBV7 & 0.64 & $233370 \pm 2558$ & $91934 \pm 6118$ & $2.5 \pm 0.14$ \\
\hline PHBV11 & 0.65 & $203018 \pm 351$ & $63276 \pm 866$ & $3.2 \pm 0.05$ \\
\hline PHBHB18 & 0.15 & $158295 \pm 749$ & $60881 \pm 3199$ & $2.6 \pm 0.12$ \\
\hline PHBHB13 & 0.16 & $166126 \pm 409$ & $82051 \pm 4709$ & $2.0 \pm 0.11$ \\
\hline PHBHB10+PLA+filler & 0.16 & $159336 \pm 1586$ & $81623 \pm 295$ & $2.0 \pm 0.01$ \\
\hline TPS & 0.68 & $40830 \pm 414$ & $16409 \pm 31$ & $2.5 \pm 0.03$ \\
\hline PBAT & 0.52 & $62991 \pm 100$ & $25971 \pm 16$ & $2.4 \pm 0.01$ \\
\hline PBAT+PLA & 0.02 & $78342 \pm 6469$ & $16138 \pm 307$ & $4.9 \pm 0.31$ \\
\hline PBAT+PLA+filler & 0.14 & $58523 \pm 696$ & $18215 \pm 214$ & $3.2 \pm 0.08$ \\
\hline PBS & 0.17 & $105342 \pm 378$ & $34922 \pm 30$ & $3.0 \pm 0.01$ \\
\hline PCL & 0.45 & $64264 \pm 663$ & $25490 \pm 707$ & $2.5 \pm 0.10$ \\
\hline TPU & 0.02 & $73384 \pm 156$ & $33860 \pm 291$ & $2.2 \pm 0.01$ \\
\hline BioPE & 0.31 & - & - & - \\
\hline
\end{tabular}

Table 3. Crystallinity, weight and number average molecular weight and polydispersity index of the biopolymers. 


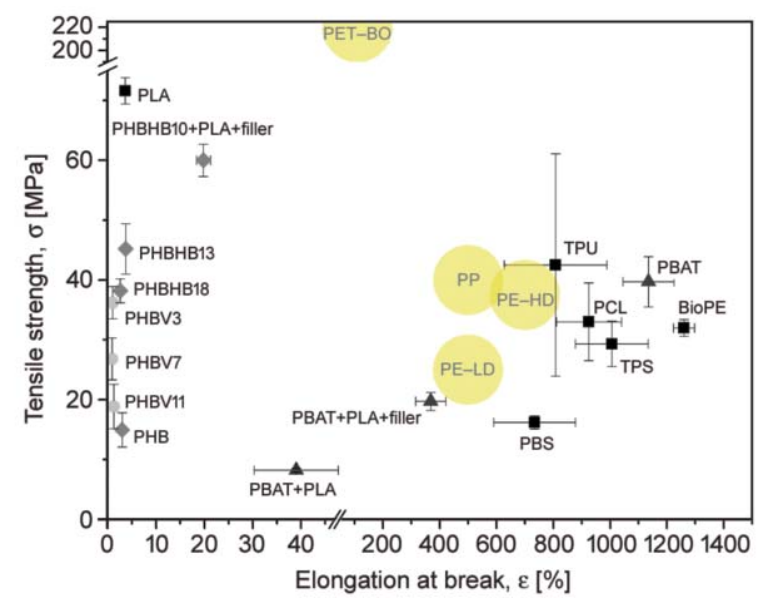

Figure 2. Tensile strength $\sigma$ versus elongation at break $\varepsilon$ for biopolymers with PHBV (•), PHBHB ( $\bullet)$, PBATbased materials $(\boldsymbol{\Delta})$ compared with conventional polymers (०) according to the literature [17]: $\sigma[\mathrm{MPa}] / \varepsilon[\%]$ of PE-LD (25/500), PE-HD (37.5/ 700), PET-BO (220 / 110), PP (40/500).

had a high $\sigma$ and high $\varepsilon$ (Figure 2), indicating their status as versatile materials having possible application as additives. Results for PBAT show that upon blending with PLA the $Y M$ slightly increases, while an additional filler significantly increases $Y M$. The addition of PLA to PBAT leads to a dramatic decrease in $\sigma$ and $\varepsilon$, while an additional filler lessens this decrease. This might be due to the low miscibility of the two biopolymers $[15,16]$. However, compared to pure PLA, the $Y M$ and $\sigma$ significantly decrease while $\varepsilon$ increases (in agreement with the literature [16]). The addition of PLA+filler to PHBHB leads, however, to an increased $Y M$ and $\sigma$. This is probably due to good stabilisation of the PHBHB-PLA system and subsequent domination of these properties by PLA. Additionally, the $\varepsilon$ of this material is extremely high probably due to the effect of the filler. Comparison with the mechanical properties of conventional materials according to the literature highlights the current opportunities for biopolymer films (see the comparison in Figures 1 and 2). Biopolymers show a wide range of mechanical properties. However, a single biopolymer usually does not possess all the equivalent properties of a conventional material.

Among the PHAs, PHBHB films showed the highest $\sigma$ and $\varepsilon$ probably due to a higher packaging density of the polymer chains compared to PHBV (with a longer side chain). By increasing the $3 \mathrm{HB}$ content in PHBHB, meaning an increased amount of methyl side chain, $\sigma$ and $\varepsilon$ are reduced. This is possibly due to the reduced packaging density and thereby reduced intermolecular interactions between the polymer chains. The pure PHB (P3HB) film has a comparatively low $Y M$ and $\sigma$. The properties of the PHBV films, with lower $\sigma$ and $\varepsilon$ than the PHBHB films, show a dependency on the $3 \mathrm{HV}$ content: With increasing $3 \mathrm{HV}$ content both $Y M$ and $\sigma$ decrease significantly while there is only a minor increase in $\varepsilon$. These results agree with the literature [18] (single sheets processed via compression moulding).

The permeation properties of the biopolymers are illustrated in Figure 3. The biopolymers with a comparatively high water vapour permeability $(W V P)$ and oxygen permeability $(O P)$ are TPS, PCL, TPU, PBAT+PLA and PBAT. These are also the biopolymers with comaratively low $Y M$ as well as high $\sigma$ and $\varepsilon$ (except PBAT+PLA). The extremely low $W V P$ and high $O P$ of BioPE is due to its apolar properties, analagous to fossil based PE-LD (Figure 3). Blending PBAT with PLA only leads to a slight increase in $W V P$ and $O P$ (compared to pure PBAT), probably due to the low miscibility of the two biopolymers $[15,16]$. However, an additional filler (PBAT+ PLA+ filler) leads to a dramatic decrease in both $W V P$ and $O P$ showing the effectiveness of this additive for the material. For comparison, the $W V P$ and $O P$ values of conventional polymers (taken from the literature) are included in Figure 3, highlighting the potential of biopolymers as packaging materials for oxygen sensitive products. However, the significantly higher $W V P$ of biopolymers is evident.

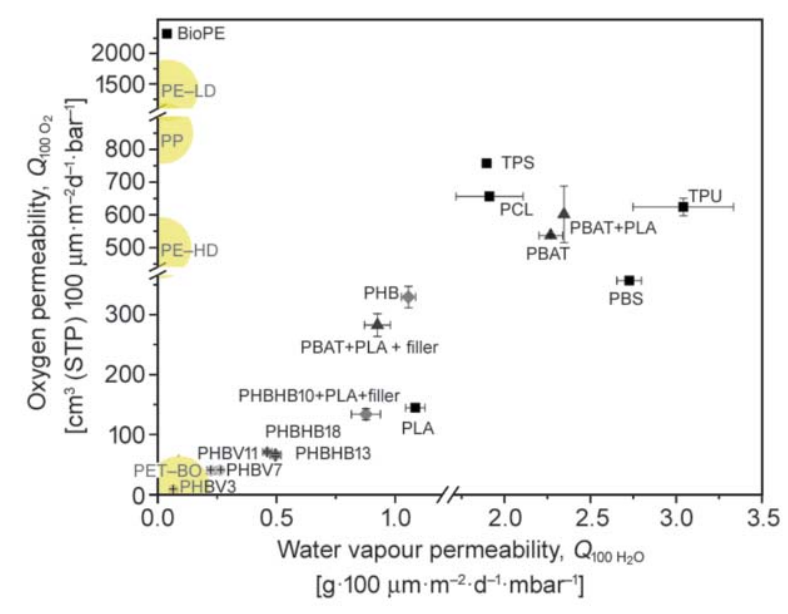

Figure 3. Oxygen permeability $\mathrm{Q}_{100 \mathrm{O}_{2}}$ versus water vapour permeability $\mathrm{Q}_{100 \mathrm{H}_{2} \mathrm{O}}$ for biopolymers with $\mathrm{PHBV}$ $(\bullet)$, PHBHB ( $)$, PBAT-based materials $(\Delta)$ compared with conventional polymers $(\odot)$ according to the literature [17]:

$\mathrm{Q}_{100 \mathrm{O}_{2}}\left[\mathrm{~cm}^{3}\right.$ (STP) $\left.100 \mu \mathrm{m} \cdot \mathrm{m}^{-2} \cdot \mathrm{d}^{-1} \cdot \mathrm{bar}^{-1}\right] /$

$\mathrm{Q}_{100 \mathrm{H}_{2} \mathrm{O}}\left[\mathrm{g} \cdot 100 \mu \mathrm{m} \cdot \mathrm{m}^{-2} \cdot \mathrm{d}^{-1} \cdot \mathrm{mbar}^{-1}\right]$ of PE-LD (1.400/0.04), PE-HD (500/0.01), PET-BO (13/0.09), PP $(850 / 0.02)$. 
Biopolymers with low permeability are particularly PHAs, followed by PLA. The permeabilities of the PHBHB samples are not significantly dependent on the $3 \mathrm{HB}$ content. A combination of PHBHB with PLA+filler increases both the $W V P$ and $O P$ significantly. This is probably due to several overlapping effects, for example the effect of the filler and the poorly miscible biopolymers $[19,20]$. Unfortunately this could not be studied in detail due to the lack of availability of commercial grades. PHBV films have lower permeabilities than PHBHB films and had the lowest permeabilities measured in this study. The permeabilities are dependent on the $3 \mathrm{HV}$ content: Increasing the $3 \mathrm{HV}$ content leads to increased $W V P$ and $O P$. This is in agreement with the literature [21] which attributed this effect to the decreased crystallinity. This could lead to a higher diffusion coefficient because diffusion is restricted to the amorphous regions and the diffusion path length is reduced. Additionally, an increasing number of side chains reduces the packaging density of the polymer chains and thereby increases the free volume. This also leads to a higher diffusion coefficient. However, the measurements showed an increased permeability and reduced crystallinity of PHBV7 and PHBV11 compared to PHBV3 but there was no significant difference in the permeability and crystallinity of PHBV7 and PHBV11. The PHBV11 film had a higher crystallinity than expected and hence a lower permeability which could be explained by its higher $M_{\mathrm{w}}$ and PDI compared to PHBV7.

\section{Conclusions}

An overview of the mechanical and permeation properties of several commercially available biopolymers extruded as cast films was presented. Analysis of the crystallinity showed that PHBV and TPS films have the highest crystallinity, followed by PBAT, PHB and PCL. Films of PBAT+PLA and TPU have extremely low crystallinity. The crystallinity of PHBV is reduced when the $3 \mathrm{HV}$ content is increased, and the crystallinity of PBAT is reduced when combined with PLA. The $M_{\mathrm{w}}$ analyses indicate that PHBV films have the highest $M_{\mathrm{w}}$, followed by PHB, PLA and PHBHB. The lowest $M_{\mathrm{w}}$ was measured for TPS, PBAT+PLA+filler, PBAT, PCL, TPU and PBAT+PLA. The mechanical analyses highlighted the high strength and extremely low elongation at break of PLA and PHA films. Several other biopolymer films showed a comparable strength but at the same time had a significantly higher elongation at break such as TPU, PCL, TPS, PBAT and BioPE. For both of the two analysed biopolymers, an additional filler leads to increased elasticity and elongation at break (measured for PBAT+PLA and PHBHB). However, the addition of PLA to PBAT leads to reduced strength and elongation at break as well as slightly increased elasticity. Among the PHAs, PHBHB films have a higher strength and elongation at break than PHBV films. The amount of copolymer is thereby decisive for the film properties: Increasing the $3 \mathrm{HB}$ content leads to reduced strength and elongation at break, while increasing the $3 \mathrm{HV}$ content leads to reduced strength and elasticity. Most of the biopolymers with comparatively low elasticity and high strength and elongation at break show relatively high water vapour and oxygen permeability. Examples of this are TPS, PCL, TPU and PBAT. In contrast, PHA films which have the highest elasticity (excluding PLA) showed the lowest permeabilities in this study. Although the addition of PLA to PBAT has only a minor effect on the permeability, an additional filler can decrease the permeability dramatically. For PHA films, the copolymer affects the permeation properties: PHBV films have lower permeabilites than PHBHB films. Moreover, the $3 \mathrm{HV}$ content affects the permeability, while the $3 \mathrm{HB}$ content does not. This study shows that biopolymers with a high $M_{\mathrm{w}}$ generally have high strength, low elongation at break and low permeability while biopolymers with a low $M_{\mathrm{w}}$ are more flexible and have higher permeability, particularly to oxygen. This overview provides a basis for selecting biopolymers which are already commercially available to replace conventional packaging materials.

\section{Acknowledgements}

The author would like to thank Tanja Fell for the molecular weight analyses.

\section{References}

[1] Endres H-J., Siebert-Raths A.: Engineering biopolymers: Markets, manufacturing, properties and applications. Hanser, München (2011).

[2] Zeng C., Zhang N-W., Ren J.: Synthesis and properties of bio-based thermoplastic polyurethane based on poly (L-lactic acid) copolymer polydiol. Journal of Applied Polymer Science, 125, 2564-2576 (2012). https://doi.org/10.1002/app.36283 
[3] Omrani I., Farhadian A., Babanejad N., Shendi H. K., Ahmadi A., Nabid M. R.: Synthesis of novel high primary hydroxyl functionality polyol from sunflower oil using thiol-yne reaction and their application in polyurethane coating. European Polymer Journal, 82, 220-231 (2016).

https://doi.org/10.1016/j.eurpolymj.2016.07.021

[4] Nguyen Dang L., Le Hoang S., Malin M., Weisser J., Walter T., Schnabelrauch M., Seppälä J.: Synthesis and characterization of castor oil-segmented thermoplastic polyurethane with controlled mechanical properties. European Polymer Journal, 81, 129-137 (2016). https://doi.org/10.1016/j.eurpolymj.2016.05.024

[5] Ryynänen T., Nykänen A., Seppälä J. V.: Poly(CL/DLLAb-CL) multiblock copolymers as biodegradable thermoplastic elastomers. Express Polymer Letters, 2, 184 193 (2008).

https://doi.org/10.3144/expresspolymlett.2008.23

[6] Fischer E. W., Sterzel H. J., Wegner G.: Investigation of the structure of solution grown crystals of lactide copolymers by means of chemical reactions. KolloidZeitschrift und Zeitschrift für Polymere, 251, 980-990 (1973).

https://doi.org/10.1007/bf01498927

[7] Barham P. J., Keller A., Otun E. L., Holmes P. A.: Crystallization and morphology of a bacterial thermoplastic: Poly-3-hydroxybutyrate. Journal of Materials Science, 19, 2781-2794 (1984). https://doi.org/10.1007/BF01026954

[8] Jost V., Schwarz M., Langowski H-C.: Investigation of the 3-hydroxyvalerate content and degree of crystallinity of P3HB-co-3HV cast films using Raman spectroscopy. Polymer, 133, 160-170 (2017). https://doi.org/10.1016/j.polymer.2017.11.026

[9] van Soest J. J. G., Benes K., de Wit D., Vliegenthart J. F. G.: The influence of starch molecular mass on the properties of extruded thermoplastic starch. Polymer, 37, 3543-3552 (1996). https://doi.org/10.1016/0032-3861(96)00165-6

[10] Sievert D., Holm J.: Determination of amylose by differential scanning calorimetry. Starch-Starke, 45, 136139 (1993).

https://doi.org/10.1002/star.19930450405

[11] Herrera R., Franco L., Rodríguez-Galán A., Puiggalí J.: Characterization and degradation behavior of poly(butylene adipate-co-terephthalate)s. Journal of Polymer Science Part A: Polymer Chemistry, 40, 4141-4157 (2002). https://doi.org/10.1002/pola.10501
[12] Miyata T., Masuko T.: Crystallization behaviour of poly(tetramethylene succinate). Polymer, 39, 1399-1404 (1998).

https://doi.org/10.1016/s0032-3861(97)00418-7

[13] Khambatta F. B., Warner F., Russell T., Stein R. S.: Small-angle $\mathrm{X}$-ray and light scattering studies of the morphology of blends of poly( $\epsilon$-caprolactone) with poly(vinyl chloride). Journal of Polymer Science Part B: Polymer Physics, 14, 1391-1424 (1976). https://doi.org/10.1002/pol.1976.180140805

[14] Turi E. A.: Thermal characterization of polymeric materials, Vol. 1. Academic Press, New York (1997).

[15] Yeh J-T., Tsou C-H., Huang C-Y., Chen K-N., Wu C-S., Chai W-L.: Compatible and crystallization properties of poly(lactic acid)/poly(butylene adipate-co-terephthalate) blends. Journal of Applied Polymer Science, 116, 680-687 (2010). https://doi.org/10.1002/app.30907

[16] Jiang L., Wolcott M. P., Zhang J.: Study of biodegradable polylactide/poly(butylene adipate-co-terephthalate) blends. Biomacromolecules, 7, 199-207 (2006). https://doi.org/10.1021/bm050581q

[17] Bleisch G., Goldhahn H., Schricker G., Vogt H.: Lexikon verpackungstechnik. Behr's Verlag, Hamburg (2014).

[18] Modi S., Koelling K., Vodovotz Y.: Assessment of phb with varying hydroxyvalerate content for potential packaging applications. European Polymer Journal, 47, 179-186 (2011). https://doi.org/10.1016/j.eurpolymj.2010.11.010

[19] Nanda M. R., Misra M., Mohanty A. K.: The effects of process engineering on the performance of PLA and PHBV blends. Macromolecular Materials and Engineering, 296, 719-728 (2011). https://doi.org/10.1002/mame.201000417

[20] Jost V., Kopitzky R.: Blending of polyhydroxybutyrateco-valerate with polylactic acid for packaging applications - Reflections on miscibility and effects on the mechanical and barrier properties. Chemical and Biochemical Engineering Quarterly, 29, 221-246 (2015). https://doi.org/10.15255/CABEQ.2014.2257

[21] Shogren R.: Water vapor permeability of biodegradable polymers. Journal of Environmental Polymer Degradation, 5, 91-95 (1997). https://doi.org/10.1007/bf02763592 